\title{
Thermal Performance of Loop Thermosyphon Charged by Nanofluid for Cooling Electronic Component

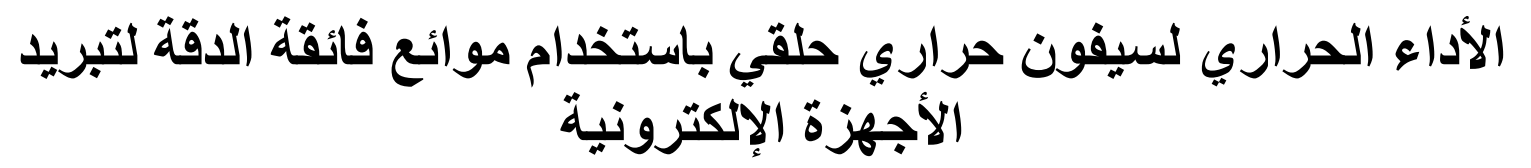

\author{
M.G.Mousa*, Hamed Eltahan** and Roaya Mahmood Jaleel \\ *Mechanical power Engineering Dept., Faculty of Engineering, Mansoura \\ University, Mansoura, Egypt \\ ** Mechanical power Engineering Dept., Faculty of Engineering, Fayoum \\ University, Fayoum, Egypt
}

\begin{abstract}
الملخص

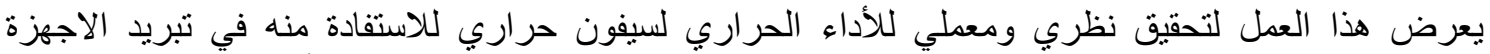

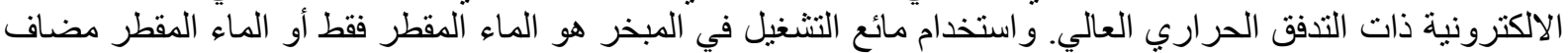

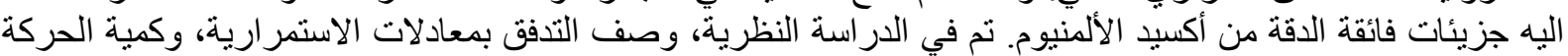

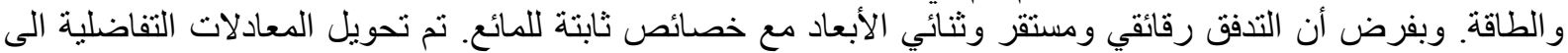

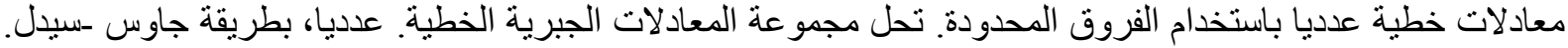

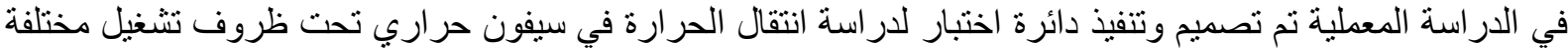

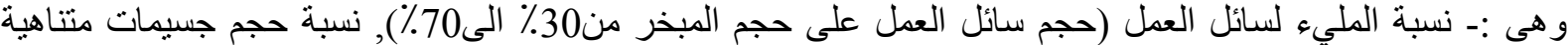

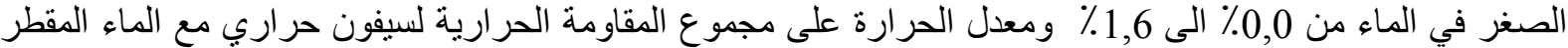

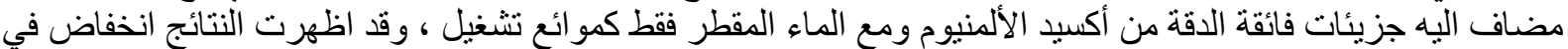

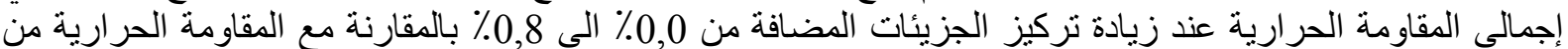

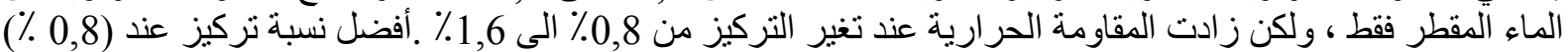

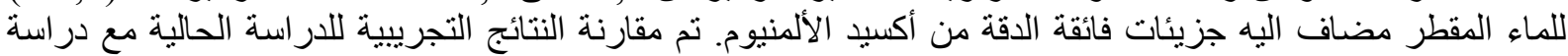
سابقة متاحة
\end{abstract}

\section{Abstract}

This work presents a theoretical and experimental investigation on the thermal performance of thermosyphon for cooling high heat flux. The working fluid charged in the evaporator is pure water or Nano fluid $\left(\mathrm{Al}_{2} \mathrm{O}_{3}+\right.$ water). In theoretical model, the flow is described by continuity, momentum and energy equations. The flow is assumed laminar, steady and two dimensional with constant properties. The differential forms of governing equations are, numerically, solved using finite difference technique. According to this technique, the partial differentials are transformed to set of linear algebraic equations. These equations are solved, numerically, by Gauss-Siedel iterative method. an experimental set up is design and constructed to study its under different operating To investigation the effect of parameters; - working fluid filling ratio (volume of working fluid to the evaporator volume (30\%, to $70 \%)$ ), volume fraction of nanoparticle in the base fluid $0.0 \%$, to $1.6 \%$. , heat input rate total thermal resistance of the thermosyphon with the Nano fluid and with pure water. Results show that the addition of $0.8 \%$ (by volume) of $\mathrm{Al}_{2} \mathrm{O}_{3}$ nano-particles in water presented improved thermal performance compared with the operation with pure water. Results showed that the total thermal resistance decreases with increasing particles from $0 \%$ to $0.8 \%$ concentration, as compared with those of pure water., but they increased as the concentration changed from $0.8 \%$ to $1.6 \%$. Thus found an optimal particle which was about $0.8 \%$ for the. Al2O3-water based nanofluid. The experimental data are compared with the available literature.

\section{Keywords}

Two phase loop, Thermosyphon, Thermal Performance, Nano fluids 


\begin{tabular}{|c|c|c|}
\hline \multicolumn{2}{|r|}{ Nomenclature } & Subscript \\
\hline & Specific heat at constant pressure .....J $/ \mathrm{kgK}$ & Condenser \\
\hline $\mathrm{P}$ & Pressure...............................bar & Evaporator \\
\hline $\mathrm{g}_{\mathrm{y}}$ & Acceleration due to gravity in $\mathrm{y}$-direction. $\mathrm{m} / \mathrm{s}^{2}$ & Nano fluid \\
\hline $\mathrm{k}$ & Thermal conductivity . . . . . . ....W/m.K & Base fluid \\
\hline $\mathrm{T}$ & Temperature . . ................ & \\
\hline $\mathrm{u}$ & Velocity in r-direction $\ldots \ldots \ldots \ldots \ldots \mathrm{m} / \mathrm{s}$ & \\
\hline $\mathrm{v}$ & Velocity in y-direction. . . . . . . .........m/s & \\
\hline Q & Input heat rate $\ldots \ldots \ldots \ldots \ldots \ldots \ldots \ldots \ldots W$ & \\
\hline TR & Total thermal resistance................. & \\
\hline $\mathrm{R}$ & Heater Resistance .................... $\Omega$ & \\
\hline \multicolumn{2}{|r|}{ Greek symbols } & Abbreviations \\
\hline & 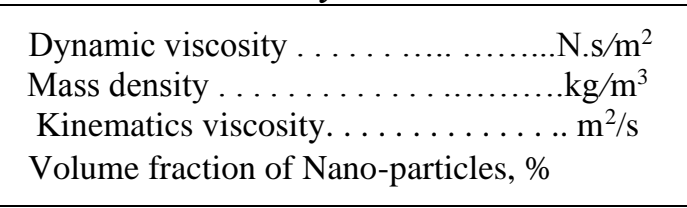 & $\begin{array}{l}\text { FR Filling Ratio of the working fluid } \\
\left(V_{l} / V_{e}\right) \text { at room temperature } \\
\text { TPCT two phase closed thermosyphon } \\
\text { CFD Computational fluid dynamics } \\
\text { RR Reduction factor in thermal resistance, }\end{array}$ \\
\hline
\end{tabular}

\section{Introduction}

The thermal management of electronic components becomes an important and serious issue. Miniaturization of devices and increase their performance leads to increased heat flow. Natural and forced cooling for heat sink are often deficient and thus is limited to low and medium heat flux .However, for higher frequency (above $1000 \mathrm{MHz}$ ), the aircooled heat sinks have some limitations in the form of bulky size, noise and insufficient cooling performance. As a result, current practice of dense packaging of electronics in compact spaces demands novel ways of heat dissipation, which will be able to dissipate as much as $100 \mathrm{~W} / \mathrm{cm} 2$ at chip levels while maintaining the device at acceptable temperatures, typically below $85^{\circ} \mathrm{C}$.

One possibility for heat dissipation for high heat flux is using thermosyphon loop to better describe the modeling domain. The thermosyphon is a very simple and very efficient heat transfer device. Basically, it can be considered a superthermal conductor that transmits heat at small temperature difference by evaporation and condensation of the working fluid. Fluids with nanoparticles (particles smaller than $100 \mathrm{~nm}$ ) suspended in them are called Nano fluids that they have a great potential in heat transfer enhancement. The thermosyphon utilizes the local gravitational acceleration for the return of condensate from the condenser to the evaporator.

\subsection{Closed two-phase loop thermosyphon Construction}

A closed two -phase thermosyphon consists of three distinct regions:

- An evaporator (heat addition region).

- A condenser (heat rejection region).

- An adiabatic (isothermal region)

\subsection{Thermosyphon Operation Principles}

As illustrated in Fig. (1.1) heat that is added to the bottom portion of a thermosyphon, tends to vaporize the working fluid. During this change process phase, the fluid picks up the heat associated with its latent heat of vaporization. Because the vapor in the evaporator region is at both a higher temperature, and pressure than the vapor in the condenser, the vapor rises and flows to the cooler condenser where it gives up its latent heat of vaporization (buoyancy forces assist this process). Gravitational forces then cause the condensate film to flow back down the inside wall of the thermosyphon where it can again be vaporized. The inside surface of a thermosyphon may occasionally be lined with grooves or a porous structure to promote return of the condensate to the 
evaporator or increase the heat transfer coefficient. Thermosyphons principally rely upon the local gravitational acceleration for the return of the liquid from the condenser to the evaporator.

\subsection{Details of the Thermosyphon Components}

The most important components of the thermosyphon are the container and the working fluid. The choice of each has a noticeable effect on the working performance of the thermosyphon and therefore, proper selection for the required purpose is very important in the design of thermosyphon.

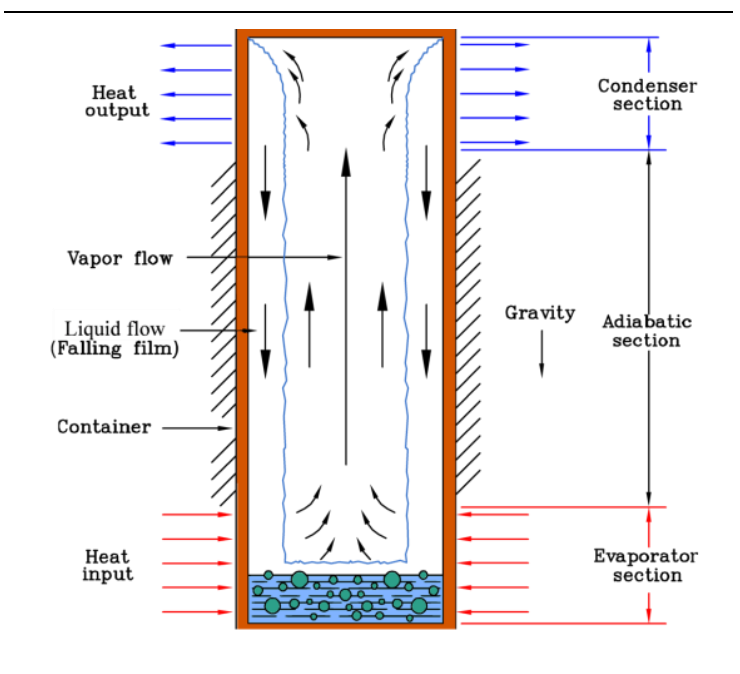

Fig (1.1) Schematic of a (TPCT)

\subsection{Nanofluid as working fluid}

The term 'Nano fluids' is used to indicate a newly introduced special class of heat transfer fluids that contain nanoparticles $(<\sim 100 \mathrm{~nm})$ of metallic/nonmetallic substances uniformly and stably suspended in a conventional heat transfer liquid. Recent studies have indicated heat by adding nanoparticles to conventional fluids can alter the thermo physical and transport properties of the base fluid.

Thus, the introduction of Nano fluids has given an impetus to the idea of developing tailor made fluids best suited for a given heat transfer application. Therefore, in principle, a working fluid with 'better' thermo physical properties can be engineered/tailor-made to potentially enhance the device performance. Nanofluids exhibit enhanced thermal properties, amongst them; higher thermal conductivity and heat transfer coefficients compared to the base fluid. Simulations for the cooling system the following emerging key features of the nanofluids:

1) Enhanced thermal conductivities as compared to conventional Solidliquid suspensions.

2) Strongly non-linear temperature dependent effective thermal Conductivity.

3) An increase in single-phase heat transfer coefficient while a decrease in pool boiling heat transfer coefficient.

4) An increase in $\mathrm{CHF}$ (critical heat flux) under pool boiling conditions.

5) Change in specific heat, density, and viscosity

\subsection{Physical properties of nanofluid}

The physical properties of nanoparticles and nanofluids are very important information for deepening the understanding of the mechanisms behind the anomalous increase in thermal conductivity of nanofluids, and, these properties are going to be used to evaluate the performance of the nanofluids as well as the potential applications of nanofluids. Thus, the effective physical properties are described by classical formulas as:[17,18] The density of nanofluids, $\square \rho_{\mathrm{nf}}$ can be simply estimated as,

$\rho_{\mathrm{nf}}=(1-\phi) \rho_{\mathrm{m}}+\phi \rho_{\mathrm{p}}$

The specific volumetric heat capacity of a nanofluid, can be calculated by a similar equation,

$$
\begin{aligned}
\rho_{\mathrm{nf}} \mathrm{Cp}_{\mathrm{nf}} & =(1-\mathrm{c}) \square \rho_{\mathrm{m}} \mathrm{C} \mathrm{p}_{\mathrm{m}}+\phi \rho_{\mathrm{p}} \mathrm{C} \mathrm{p}_{\mathrm{p}} \\
\boldsymbol{\mu}_{\mathrm{nf}} & =\boldsymbol{\mu}_{\mathrm{m}} \frac{\mathbf{1}}{(\mathbf{1}-\boldsymbol{\phi})^{2.5}}
\end{aligned}
$$

Effective thermal conductivity of composites or nanofluids, $\boldsymbol{k}_{\boldsymbol{n}}$, are dependent only on the thermal conductivity 
of base fluids, $\boldsymbol{k}_{\boldsymbol{m}}$, the thermal conductivity of dispersed particles, $\boldsymbol{k}_{\boldsymbol{p}}$, and the volumetric fraction of particles, and can be expressed as,

$$
\mathrm{k}_{\mathrm{nf}}=\mathrm{k}_{\mathrm{m}} \frac{\mathrm{k}_{\mathrm{p}}+2 \mathrm{k}_{\mathrm{m}}+2\left(\mathrm{k}_{\mathrm{p}}-\mathrm{k}_{\mathrm{m}}\right) \phi}{\mathrm{k}_{\mathrm{p}}+2 \mathrm{k}_{\mathrm{m}}-\left(\mathrm{k}_{\mathrm{p}}-\mathrm{k}_{\mathrm{m}}\right) \phi}
$$

The relevant thermo-physical properties of the solid Nano-particles $\left(\mathrm{Al}_{2} \mathrm{O}_{3}\right)$ used in the present study are: $\mathrm{Cp}_{\mathrm{p}}=773 \mathrm{~J} / \mathrm{kg} \cdot \dot{\mathrm{C}}, \rho=3880 \mathrm{~kg} / \mathrm{m}^{3}$, and $\mathrm{k}_{\mathrm{p}}=36$ W/m. C .from $[17,18]$.

\section{Literature Review}

The history of heat pipes and two phase thermosyphons probably starts with the invention of the Perkins tube, which was patented in 1836 . This was basically a thermosyphon pipe, or loop, and it was used for example to transfer heat from furnaces to baking ovens (Dunn and Reay) [1]. Khodabandeh, R. [2] studied Heat transfer in the evaporator of an advanced two-phase thermosyphon loop and he found that heat transfer is weakly dependent on vapor fraction but highly dependent on heat flux and system pressure, indicating that nucleate boiling is the dominant mechanism and for different diameters of evaporator channels the heat transfer coefficient slightly increases with increasing vapor fraction. Palm and Khodabandeh,[3] studied the parameters taken into account for choosing working fluid for two-phase thermosyphon systems for cooling of electronics and they found that increased pressure level generally leads to lower temperature difference and smaller tubing diameter. It has been stated that there are no ideal working fluids. McDonald et al, [4] studied thermosyphon loop performance characteristics and they found that for a given loop orientation and charge the performance will be affected by changes in the source and sink temperatures. For a given source, sink temperature difference the performance was found to be improved with increasing loop pressure. Mehta and Khandekar [5] and Khandekar et al [6and 7] investigated experimentally the overall thermal resistance of a closed twophase thermosyphon using pure water and various water based nanofluids (of $\mathrm{Al}_{2} \mathrm{O}_{3}$, $\mathrm{CuO}$ and Laponiteclay) as working fluids. All these nanofluids were showing the thermal performance greater than pure water. The behavior of nanofluids is explained in the light of pool boiling dynamics and the interplay of nucleating cavities with wettability of the nanofluids.

\subsection{Nano fluid as working fluid}

The traditional working fluids have poor heat transfer properties compared to most solids. Therefore, Argonne National Laboratory has developed a new class of heat transfer fluids called "Nanofluids", which are engineered by suspending ultrafine of metallic or nonmetallic nanometer dimension particles in traditional fluids such as water, engine oil, ethylene glycol by Choi, and Eastman [8].

Das et al. [9] showed that effective thermal conductivity of nanofluids increases with increase in temperature. This finding makes nanofluids even more attractive as a cooling fluid for devices with high energy density. Past few years have seen many researches involved in measurement of single phase convective heat transfer rates using nanofluids with many groups reporting increase in forced convection rates. You et al. [10] have also reported the deterioration in boiling heat transfer coefficient but found drastic enhancement in critical heat flux (CHF) for $\mathrm{A} 12 \mathrm{O} 3$ nanofluids. They performed visualization study and found that the average size of departing bubble increases but the frequency of departing bubble decreases. Bang and Chang, [11] studied the boiling heat transfer using Al2O3-water nanofluids on a horizontal smooth surface. They showed that nanofluids have poor heat transfer coefficients compared to pure water in natural convection as well as in nucleate boiling. They also reported enhancement in CHF in both, horizontal and vertical pool of liquid. 


\section{2 two-phase closed thermosyphon for cooling electronic}

Rhi and Lee,[12] found that a cooling heat flux of $12 \mathrm{~W} / \mathrm{cm}^{2}$ and $5 \mathrm{~W} / \mathrm{cm}^{2}$ at an overall temperature difference of $50^{\circ} \mathrm{C}$ could be achieved under forced and free convection respectively. The result was obtained during study of an advanced twophase flow thermosyphon loop for cooling of electronic components using acetone or FC87 as working liquid. Yousefi et al.[13] experimentally investigated the effects of inclination angle and nanofluids on the performance of a heat pipe used for CPU cooling. With the CPU in the horizontal position, the heat pipe was capable of cooling the CPU. Their results indicated that using $0.5 \% \quad \mathrm{Al}_{2} \mathrm{O}_{3}$-water nanofluid as the heat pipe's working fluid, the thermal resistance can be decreased by $15 \%$ and $22 \%$, when the heat generated at the CPU was at $10 \mathrm{~W}$ and $25 \mathrm{~W}$ respectively. Singlephase and two-phase heat exchangers for power electronic components were presented by Gillot et al. [14], the experiment performed to assess the feasibility of single-phase and two-phase micro heat sinks applied to the cooling of power components. After a brief recall of the principal characteristics of a power component insulated gate bipolar transistor, experimental measurements were described for multi-chip modules cooled by singlephase or two-phase heat sinks machined in a piece of copper. Two-phase loop compact thermosyphon was presented by Beitelmal et al.[15] Heat dissipation from high performance microprocessors had a limiting value of $100 \mathrm{~W} / \mathrm{cm}^{2}$. They adopted a new way to resolve the thermal challenges by developing and implementing an innovative low cost compact loop thermosyphon. Integrated thermal management techniques for high power electronic devices were presented by Mcglen et al.[16] In electronics industry, miniaturization of silicon components and enhanced performance has led to high power electronic devices with high packing densities. That has identified the future development of very high heat flux components. They reviewed the development of microprocessing technology and proposed a project to develop combined two-phase heat transfer and heat pipe technology with forced air convection and liquid condenser systems.

\section{Aim of the Present Work}

The aim of the present work is a theoretical and experimental study of the flow and heat transfer inside the thermosyphon. The operating parameter of the performance of the thermosyphon is filling ratio, volume fraction of nanoparticles and the evaporator dimension. In theoretical study the continuity, momentum and energy equations describe the flow and heat transfer inside the thermosyphon are solved. In experimental study, the thermal performance of thermosyphon cooling system in electronic equipment is also studied. The effect of different operating conditions on the thermal performance of the constructed thermosyphon. These conditions involve the type of working fluid (pure water and $\mathrm{Al}_{2} \mathrm{O}_{3}$ - water based nanofluid); filling ratio of the working fluid; volume fraction of nano- particles in the base fluid, and heat input rate.

\section{Theoretical Model}

The flow fluid and heat transfer into thermosyphon is a process very complex. In consequence, the efficiency of a thermal CFD simulation depends on many factors. Creation of the model geometry and its integration in a physical domain, grid generation and choice of a suitable numerical computing scheme are significant factors that can determine the level of success of the simulation process. The CFD code used for this study was FORTRAN which is developed to get the heat transfer coefficient and Nussle number the along condensation surface. The required input data for this program are the evaporator height, heat flux to the evaporator, kinematics viscosity for liquid, kinematics 
viscosity for vapor, thermal conductivity for liquid, evaporator temperature, condenser temperature, latent heat of water, specific heat constant at constant pressure for liquid, the absolute error is equal 0.01, number of nodes in $\mathrm{R}$ direction ( $\mathrm{n}$ ), number of nodes in $\mathrm{Y}$ direction $(\mathrm{m})$ and saturation temperature.

\subsection{Governing equations}

The governing equations for flow and heat transfer inside of the thermosyphon were solved in the Cartesian coordinate system(r, y) to express the flow governing equations. The flow is assumed laminar, steady and two dimensional with constant properties. The differential forms of governing equations are, numerically, solved using finite difference technique. According to this technique, the non-linear partial differential equations are transformed to sets of linear algebraic equations. These equations are solved, numerically, employed Gauss-Siedel iterative method. The general governing equations are the continuity, momentum, and energy equations in Cartesian coordinates. They can be written as:

$\frac{1}{\mathrm{r}} \frac{\partial(\mathrm{ru})}{\partial r}+\frac{\partial v}{\partial y}=O . O$

$\frac{u}{r} \frac{\partial(\mathrm{ru})}{\partial \mathrm{r}}+\mathrm{v} \frac{\partial \mathrm{u}}{\partial \mathrm{y}}=\frac{1}{\rho} \frac{\partial \mathrm{P}}{\partial \mathrm{r}}+\mathrm{v}\left[\frac{1}{\mathrm{r}} \frac{\partial}{\partial \mathrm{r}}\left(\mathrm{r} \frac{\partial \mathrm{u}}{\partial \mathrm{r}}\right)+\frac{\partial^{2} \mathrm{u}}{\partial \mathrm{y}^{2}}\right]$

$\frac{u}{r} \frac{\partial(\mathrm{rv})}{\partial \mathrm{r}}+\mathrm{v} \frac{\partial \mathrm{v}}{\partial \mathrm{y}}=\frac{1}{\rho} \frac{\partial \mathrm{P}}{\partial \mathrm{y}}+\mathrm{v}\left[\frac{1}{\mathrm{r}} \frac{\partial}{\partial \mathrm{r}}\left(\mathrm{r} \frac{\partial \mathrm{v}}{\partial \mathrm{r}}\right)+\frac{\partial^{2} \mathrm{v}}{\partial \mathrm{y}^{2}}\right]+\mathrm{g}_{\mathrm{y}}$

$\frac{u}{r} \frac{\partial(\mathrm{rT})}{\partial \mathrm{r}}+\mathrm{v} \frac{\partial \mathrm{T}}{\partial \mathrm{y}}=\frac{\mathrm{k}}{\rho C p}\left[\frac{1}{\mathrm{r}} \frac{\partial}{\partial \mathrm{r}}\left(\mathrm{r} \frac{\partial \mathrm{T}}{\partial \mathrm{r}}\right)+\frac{\partial^{2} \mathrm{~T}}{\partial \mathrm{y}^{2}}\right]$

Equations (4.1-4.4) are the continuity equation, momentum equation in $r$ direction, momentum equation in $y$ direction, and energy equation, respectively. Where $u, v$, and $T$ are the velocity component in r-direction, $\mathrm{v}$, velocity component in $\mathrm{x}$ - direction, temperature and $v, \rho$, and $g_{y}$ kinematics viscosity, density, gravitational acceleration in $\mathrm{x}$ directions and $q, p, k$ and $C p$ heat generation, pressure, thermal conductivity and specific heat at constant pressure, respectively.

The above equations are solved with associated boundary below:-

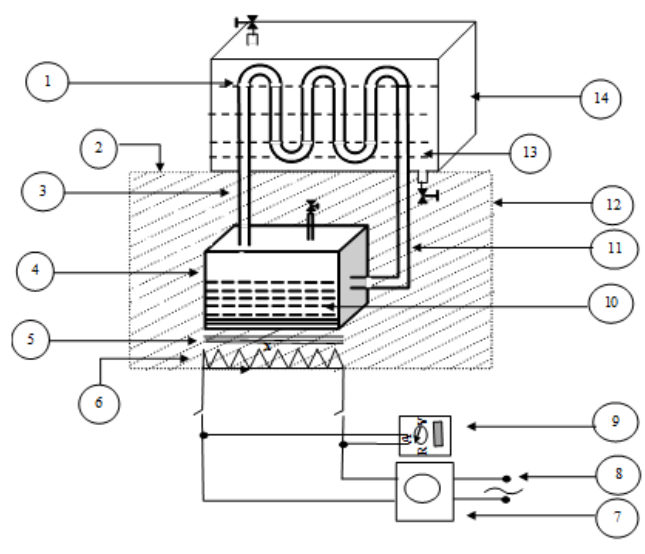

\begin{tabular}{ll|ll}
\hline 1. & Condenser & 8. & Electric power \\
2. & Insulation & 9. & Digital multimeter \\
3. & Liquid tube & 10. & Liquid in evaporator \\
4. & Evaporator & 11. & Vapor tube \\
5. & Mica sheet & 12. & Valve \\
6. & Electric heater & 13. & Water \\
7. & Autotransformer & 14. & Container cooling \\
\hline
\end{tabular}

Figure (5.1) Schematic layout of the test rig used in experimental work

a) $\mathrm{r}=0,0 \leq \mathrm{y} \leq \mathrm{L}_{\mathrm{e}}, \mathrm{u}=\mathrm{v}=0, \quad \mathrm{~T}=\mathrm{T}_{\mathrm{e}}$

b) $\mathrm{r}=0, \mathrm{~L}_{\mathrm{e}} \leq \mathrm{y} \leq \mathrm{L}_{\mathrm{e}}+\mathrm{L}_{\mathrm{a}}, \quad \mathrm{u}=\mathrm{v}=0$, $\mathrm{T}=\mathrm{T}_{\mathrm{a}}$

c) $\mathrm{r}=0, \mathrm{~L}_{\mathrm{e}}+\mathrm{L}_{\mathrm{a}} \leq \mathrm{y} \leq \mathrm{L}_{\mathrm{e}}+\mathrm{L}_{\mathrm{a}}+\mathrm{L}_{\mathrm{c}}$, $\mathrm{u}=\mathrm{v}=0, \quad \mathrm{~T}=\mathrm{T}_{\mathrm{c}}$

and solved using finite volume divided and one can get the temperature distribution along the outer surface thermoyphon the thermal resistance is defined as:

Rth $=\left(T_{e}-T_{c}\right) /$

Where, $T_{e}$ and $T_{c}$ are average values of the respective locally placed thermocouple, and $\mathrm{Q}$, input heat rate.

\section{Experimental Set-Up}

A schematic layout of the experimental set-up is shown in Fig. (5.1). The experimental set-up consists of four type thermosyphon with differ from each other in the volume of the evaporator section. The used thermosyphon consists of 
three main parts: evaporator, condenser and adiabatic tubes with thickness $1 \mathrm{~mm}$.

The evaporator (4) is made of copper cubic with different sizes as mentioned in table (5.1), the condenser (1) is constructed of three loop of copper tube: with $100 \mathrm{~mm}$ height $\left(\mathrm{L}_{\mathrm{c}}\right), 1 \mathrm{~mm}$ thickness and The adiabatic section is made of copper tubes and it is constructed of two tubes; vapor tube (11) is used to carry out the vapor from the evaporator to condenser and liquid tube (3) is used to return the condensate water from the condenser to the evaporator.

It is mounted perpendicular to condenser and evaporator sections. The adiabatic tubes are $100-\mathrm{mm}$ height $\left(\mathrm{L}_{\mathrm{a}}\right)$, $6.37 \mathrm{~mm}$ diameter $\left(\mathrm{d}_{\mathrm{a}}\right)$ and $0.85 \mathrm{~mm}$ thick. Fig (5.2) the outer dimensions of the thermosyphon. In the thermosyphon, the heat flux is generated by using electric heaters (6). Distilled water or nanofluid $\left(\mathrm{Al}_{2} \mathrm{O}_{3} /\right.$ water) (10) are used as working fluids, and the vapor generated at the evaporator section (4) is moved to the cooling section (1) (condenser) through the insulated riser tube (11). Then, the condensate returned back to evaporator by gravity through the insulated down comer (3). The adiabatic section which contains the vapor tube (11) that carries out vapor from evaporator to condenser and liquid tube (3) that returns the condensed liquid from condenser to evaporator. The evaporator bottom surface and evaporator sides are covered with $5 \mathrm{~cm}$ thickness of glass wool insulation (2). Adiabatic section, are covered with insulation.

The temperature distribution along the thermosyphon walls are measured using copper-constantan thermocouples (K-type) and digital temperature recorder arrangement through a Data acquisition system.

The electric power (8) supplied to the evaporator heater (6) is determined by monitoring the applied voltage, current and resistance using digital multimeter (9). The value of applied voltage across the electric heaters can be adjusted by using an autotransformer (VARIAC) (7). The voltage drop across the heaters can be varied from 0.0 volt to 210 volt. Figure (5.3) illustrates a photographic photo of the experimental test rig.

\begin{tabular}{|c|c|c|c|}
\hline $\begin{array}{c}\text { Test } \\
\text { section }\end{array}$ & $\begin{array}{c}\text { Height } \\
\left(\mathrm{Le}_{\mathrm{e}}\right) \\
(\mathrm{mm})\end{array}$ & $\begin{array}{c}\text { Width } \\
\left(\mathrm{W}_{\mathrm{e}}\right) \\
(\mathrm{mm})\end{array}$ & $\begin{array}{c}\text { Depth } \\
\left(\mathrm{D}_{\mathrm{e}}\right) \\
(\mathrm{mm})\end{array}$ \\
\hline 1 & $\mathbf{1 0 0}$ & $\mathbf{1 0 0}$ & $\mathbf{1 0 0}$ \\
\hline 2 & $\mathbf{1 0 0}$ & $\mathbf{1 0 0}$ & $\mathbf{5 0}$ \\
\hline 3 & $\mathbf{1 0 0}$ & $\mathbf{5 0}$ & $\mathbf{5 0}$ \\
\hline 4 & $\mathbf{5 0}$ & $\mathbf{5 0}$ & $\mathbf{5 0}$ \\
\hline
\end{tabular}

Table (5.1) Dimension used in the evaporator section.

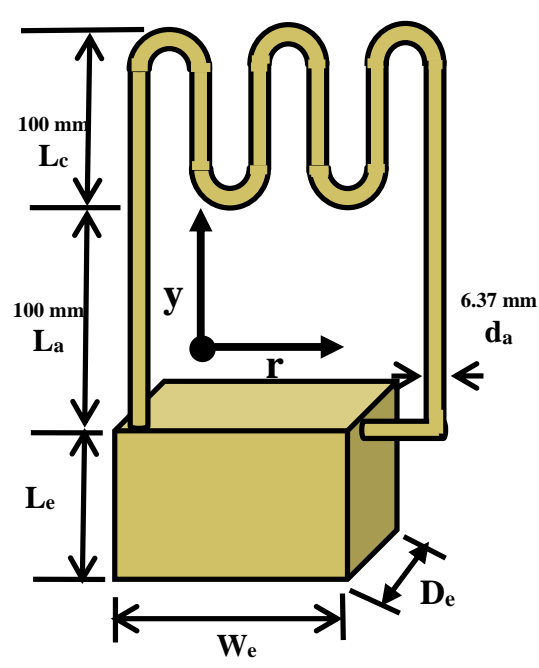

Figure (5.2) Schematic diagram for outer dimensions of the thermosyphon

\subsection{Experimental Procedure}

In the experimental work, the effect of filling ratio, FR, (volume of liquid over total evaporator volume) and heat flux are examined. The experimental runs are carried out according to the following steps:

1. The thermosyphon is evacuated and charged with a certain predetermined amount of working fluid and then the current and voltage are adjusted.

2. The supplied electrical power is manually adjusted to the desired value using the autotransformer.

3. As noted, the steady state condition is achieved after a time period of about 120 min, during which necessary 
adjustments in the input power is made. Thereafter, the readings of thermocouples, voltage are recorded as follows:

- The reading of thermocouples at the thermosyphon surface and ambient temperature are recorded sequentially using the Data acquisition system.

- The voltage and Resistance of the heater are measured to determine the value of the applied heat flux.
4. After finishing the above experimental steps, power is changed to another value and step 3 is repeated.

5. The thermosyphon is charged with another adjusted value of working fluid such that the filing ratio, FR, is changed using the following value.

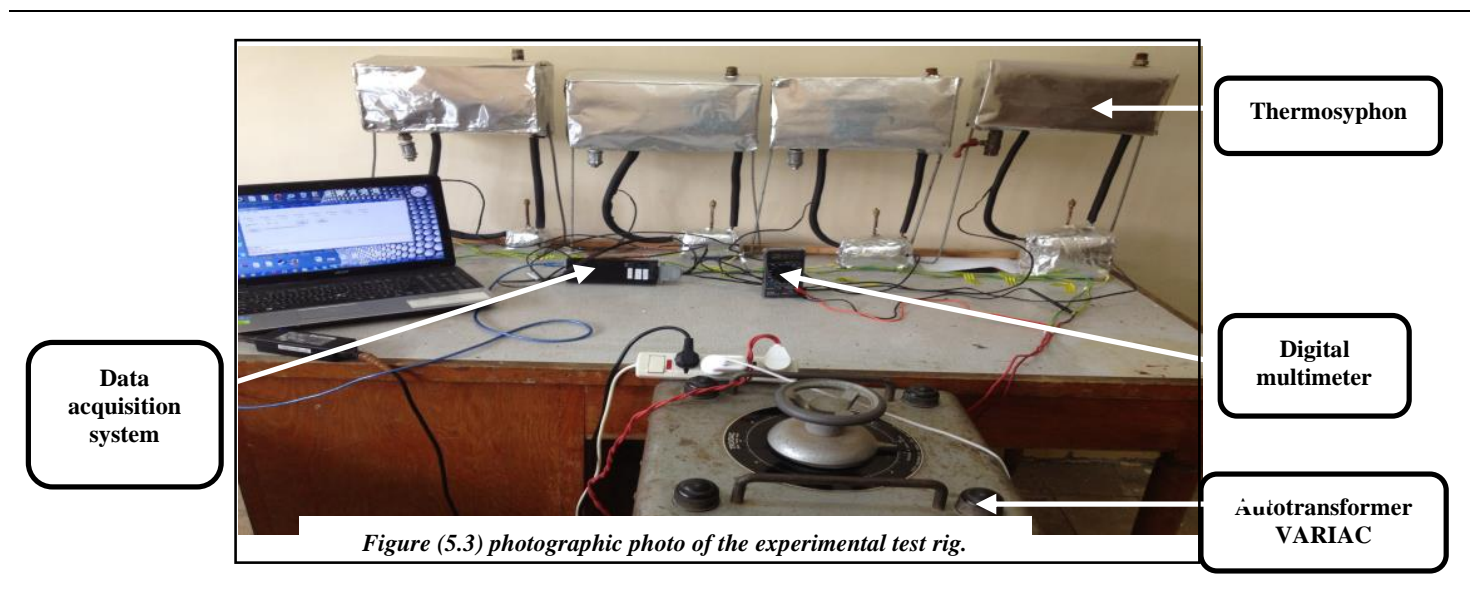

\subsection{Data Reduction}

At steady state condition, the produced heat generated by the electrical heating is given by the following equation to calculate the heat transfer rate and check the error analysis in experimental data may have resulted from

$\mathrm{Q}=\mathrm{V}^{2} / \mathrm{R}$

Where, Q, V, R are the input heat rate in watt, the applied voltage drop a cross the heat element terminals in volt and the heater resistance in ohm.

Thermocouples are used to measure the temperature distribution along the evaporator, adiabatic and condenser sections. The average evaporator and condenser temperatures can be calculated from the following equations:-

$\mathrm{T}_{\mathrm{e}=\Sigma} \mathrm{T}_{\mathrm{e}} / \mathrm{N}_{\mathrm{e}}$

$\mathrm{T}_{\mathrm{c}}=\Sigma \mathrm{T}_{\mathrm{e}} / \mathrm{N}_{\mathrm{c}}$ where $\mathrm{Te}, \mathrm{Tc}$ and $\mathrm{Nc}, \mathrm{Ne}$, are the local evaporator and condenser temperature in ${ }^{\circ} \mathrm{C}$, total number of thermocouples at the evaporator and condenser section ,respectively.

The obtained data for temperatures and heat input rate are then used to calculate the total thermal resistance using the following relation:

$\mathrm{TR}=\left(\mathrm{T}_{\mathrm{e}}-\mathrm{T}_{\mathrm{c}}\right) /{ }^{\cdot} \mathrm{Q}-$

And we can calculate the reduction factor in total thermal resistance of thermosyphon

Charged with nanofluid by referring its thermal resistance to that charged with pure water, expressed as:

$\mathrm{RR}=\left(\mathrm{TR}_{\mathrm{m}}-\mathrm{TR} \mathrm{Rf}\right) / \mathrm{TR}$

Where $\mathrm{TR}_{\mathrm{nf}}$ total thermal resistance of thermosyphon charged with nanofluid, $\mathrm{TR}_{\mathrm{m}}$ 
total thermal resistance of thermosyphon charged with base fluids (pure water).

\subsection{Results and Discussion}

This section summarizes the results of the theoretical and experiments performed on the thermosyphon system .involves the study of convective heat transfer in thermosyphon. Total thermal resistance is introduced. Using wall temperature readings, the total resistance of the tested thermosyphon is calculated for different values of operating parameters. The experiments on the thermosyphon thermal performance are carried out for the various values of input heat fluxes Distilled water and nanofluid (Al2O3/distilled water) are used as the working fluids, and are charged with a filling ratio of $30 \%, 40 \%, 45 \%, 50 \%$, $60 \%$ and $70 \%$ respectively. Nano-particle concentration, [volume concentration $(\phi)$ are value $\quad 0.2 \%, 0.4 \%, 0.6 \%, 0.8 \%, \quad 1 \%$, $1.2 \% ., 1.6 \%$ is the ratio of nanoparticles volume to total volume (base fluid volume + nanoparticles volume)] are used. Finally, the obtained experimental results are compared with the values obtained from available literature.

\subsubsection{Temperature distribution}

The values of local surface temperatures along all sections of the thermosyphon are measured. where $\mathrm{Y}$ is measured from the beginning of the evaporator section. The range $(0.0 \leq \mathrm{Y} \leq$ $100 \mathrm{~mm}$ ) represents the evaporator section, $(100<\mathrm{Y} \leq 200 \mathrm{~mm})$ represents the adiabatic section and $(200<\mathrm{Y} \leq 300 \mathrm{~mm})$ represents the condenser section. Figs (5.4) illustrate the surface temperature along the thermosyphon for three values of heat input rate $(7.43 \mathrm{~W}, 23 \mathrm{~W}, 47.34 \mathrm{~W})$ and same filling ratio, $F R$ of 0.5 , using $\mathrm{Al}_{2} \mathrm{O}_{3}$ nanofluid as working fluid with volume concentration $\phi=0.6$. As expected, the surface temperature decreases with increasing the distance from the evaporator section due to the heat exchange between the thermosyphon surface and working fluid. It is clear that the surface temperature decreases with increase of nano-particle concentration, as expected, the surface temperature decreases with increasing the distance from the evaporator along thermosyphon.

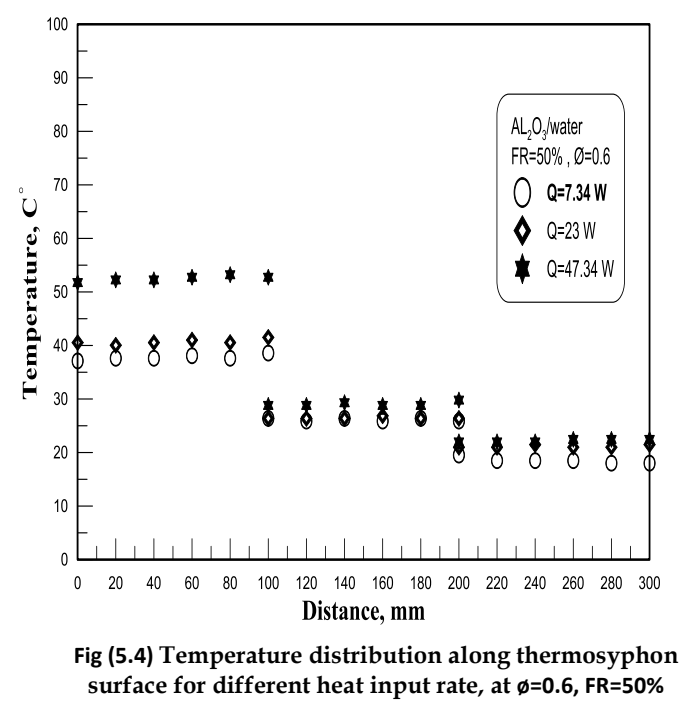

\subsubsection{Effect of filling ratio on thermal resistance}

Figures (.55) show the effect of filling ratio (FR) on thermal resistance for (TR) distilled water as a working fluid, at different heat input rates, Q. It can be noticed that, TR decreases with increasing FR up to a value of $50 \%$, after which the total thermal resistance, TR, starts to increase with increasing FR due to the increase of liquid inside the evaporator. The total thermal resistance, TR, is decreases as the heat input rate increases.

Figures (.56) show the effect of filling ratio (FR) on thermal resistance for (TR for Al2O3-water based Nano fluid at $(\phi=$ $0.6 \%$ ), at different heat input rates, Q. It can be noticed that, TR decreases with increasing FR up to a value of 50\%, after which the total thermal resistance, TR, starts to increase with increasing FR due to the increase of liquid inside the evaporator. The total thermal resistance, TR, is decreases as the heat input rate increases. 


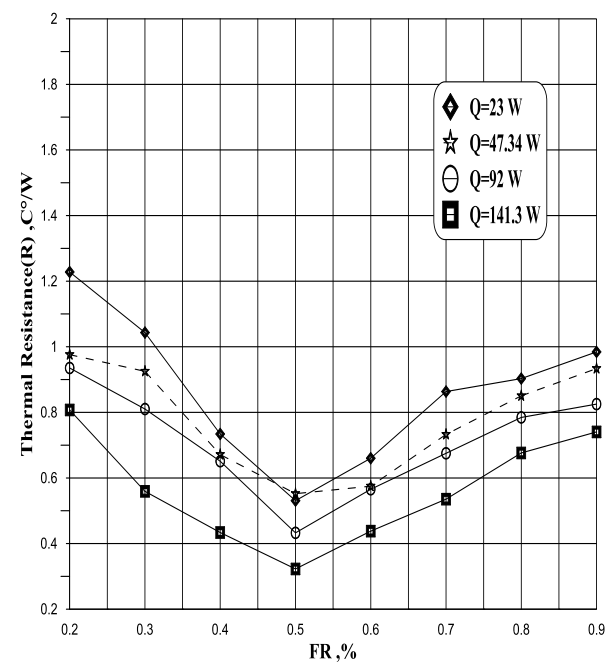

Fig (5.5) Relation between thermal resistance and filling ratio for distilled water at different heat input

\subsubsection{Effect of nanoparticles concentration on thermal resistance}

Figures (.57) show the effect of nanoparticles concentration $(\phi)$ on thermal resistance (TR) for different filling ratios (FR). this figure show the thermal resistance decreased initially with increasing the particle concentration from $0 \%$ to $0.8 \%$, but they increased as the concentration changed from $0.8 \%$ to $1.6 \%$ .thus, found an optimal particle concentration, which was about $0.8 \%$ with $\mathrm{FR}=0.5$.

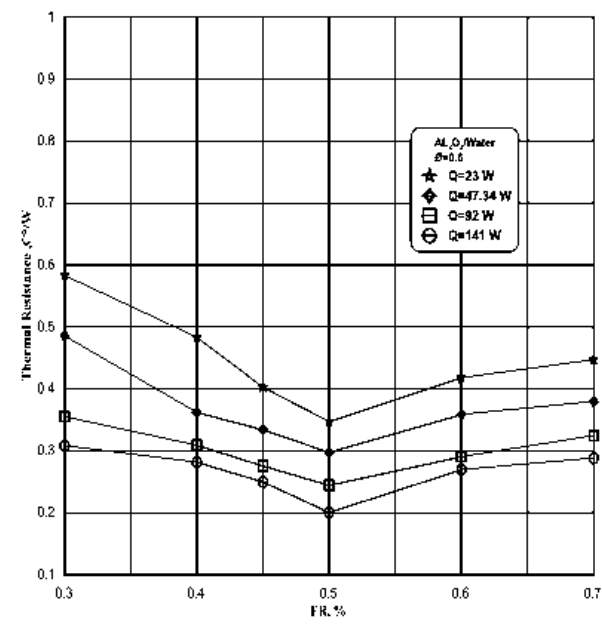

Fig.(5.6)-relation-between thermal-resistancesף and $\cdot$ filling $\cdot$ ratio $\cdot$ for $\cdot$ different $\cdot h$ heat $\cdot$ input $\cdot a t \cdot \varnothing=0.6 \uparrow$

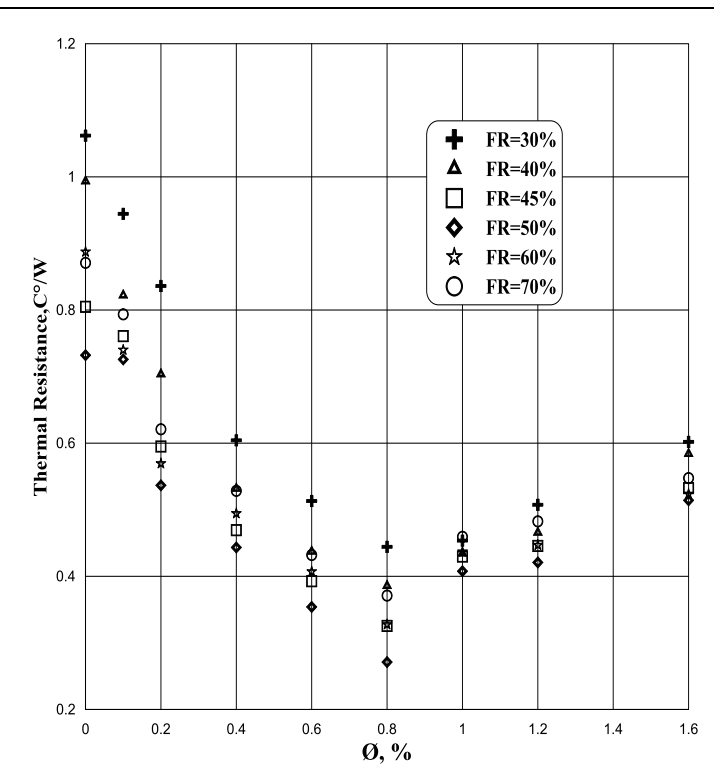

Fig (5.7) relation between thermal resistance and nanofluid concentration

\subsubsection{Reduction Rate (RR)}

The effect of adding nano-particles on the thermal performance of the thermosyphon is more evident if the data is expressed as a plot of the reduction rate in total thermal resistance, RR versus $\phi$, as shown in Fig. (8.5), the enhancement of thermal performance is increasing with the increase of nano-particles concentration $(\phi)$ from $0 \%$ to $0.8 \%$ reaches up to $(60.0 \%$ at $\phi$ $=0.8)$ compared to its value when using pure water. ,but they decreased as the concentration changed from $0.8 \%$ to $1.6 \%$ that is mean that the thermosyphon charged with nanofluid with high solid mass fraction up $(0.8 \%)$ had negative effects on thermal performance of the thermosyphon, because of the particles conglomeration and sedimentation in high concentration nanofluids. 


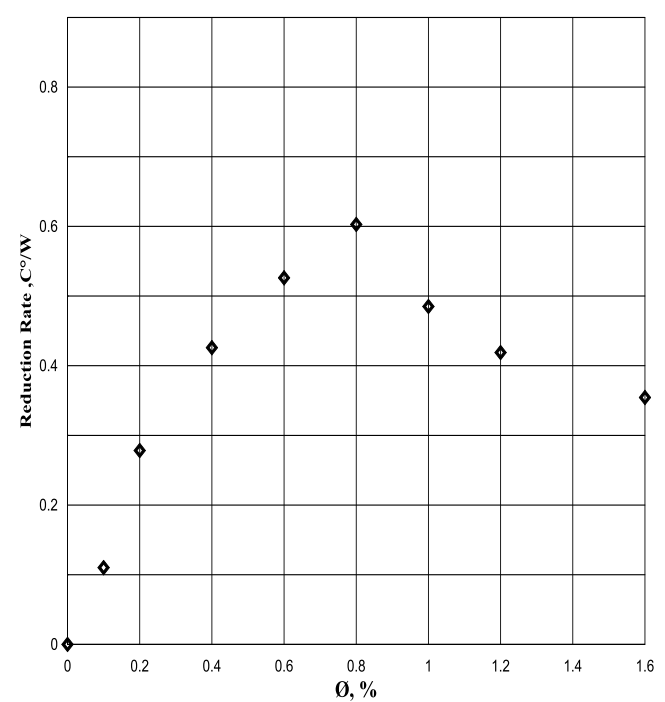

Fig (5.8) Relation between Reduction Rate (RR) and nanoparticles concentration (Ø)

The addition of nano-particles has illustrated that during nucleate boiling some nano-particles deposit on the heated surface to form a porous layer. This layer improves the wet ability of the surface considerably. The thermal conductivity of the working fluid is also preferably high in order to minimize the temperature gradient. .

Thus, the thermal resistance of the fluid will be minimized.Thermal resistance of thermosyphon is caused by the formation of vapor bubble at the liquid-solid interface. A larger bubble nucleation size creates a higher thermal resistance that prevents the transfer of heat from the solid surface to the liquid [18]. The suspended nano-particles tend to bombard the vapor bubble during the bubble formation. Therefore, it is expected that the nucleation Size of the vapor bubble is much smaller for the fluid with suspended nano-particles than that without them.

\subsubsection{Comparison between present and previous results}

Figure (5.9) shows a comparison between the present experimental results with those reported by Mousa, M. G. [19] in case of using pure water and nanofluid as a working fluid. The present and previous work take the same trend but the concentration above $1.0 \%$ the relation between Reduction Rate (RR) and nanoparticles concentration $(\varnothing)$.

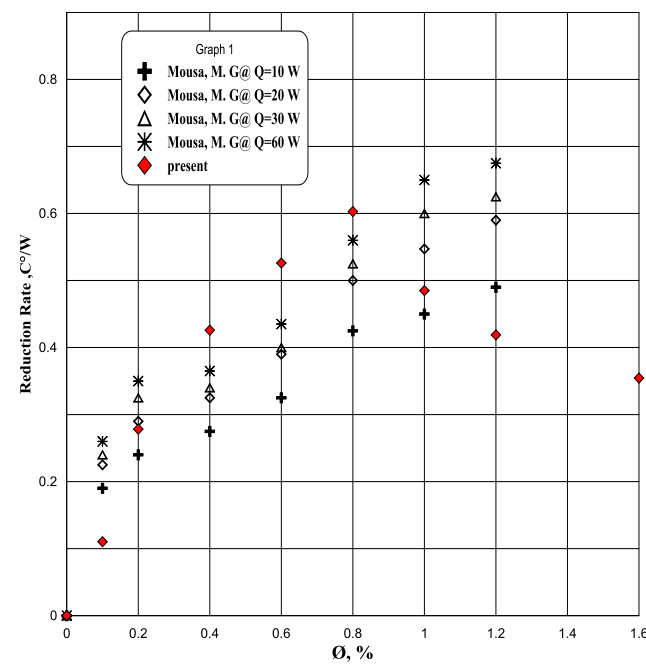

Fig (5.9) Comparison of the present results with available literature between Reduction Rate (RR) and nanoparticles concentration $(\varnothing)$

\section{6-Conclusions}

In this paper, extensive theoretical and experimental investigations have been carried out to compare the thermal performance of the thermosyphon performance, which charged with DI-water and $\mathrm{Al}_{2} \mathrm{O}_{3}$ nanofluid as the working fluid. Based on the obtained results of the present study the following conclusions may be deduced:-

1- Results indicate that the nanofluid has remarkable potential as working fluid for thermosyphon of higher thermal performances.

2- The optimum filling ratio of charged fluid was about $0.45-0.50$ for both pure water and $\mathrm{Al} 2 \mathrm{O} 3$ - water based nanofluid, respectively. To obtain high heat transfer performance.

3- Optimal particle which was about $0.8 \%$ for the. Al2O3-water based nanofluid.

4- The thermal resistance of the thermosyphon with nanoparticle solution is lower than that with DIwater. It is shown that the thermal resistance decreases as the concentration increases, but they 
decreased as the concentration changed up $\phi=0.8 \%$ 5-the thermosyphon charged with nanofluid with high solid mass fraction up $(0.8 \%)$ had negative effects on thermal performance of the thermosyphon, because of the particles conglomeration and sedimentation in high concentration nanofluids. This conclusion is true for thermosyphons. For most examined conditions, the thermal resistance is improved by about to $60 \%$ by increasing the nanofluid concentration to $\phi=0.8 \%$.

It can be said that better ability to manage thermal properties of working fluid translates into greater energy transport, smaller and lighter thermal systems. This may be applied to cooling of super computers.

\section{References}

[1] Dunn, P.D and Reay, D.A., heat pipes, $4^{\text {th }}$ ed, ISBN 0080419038, Pergamum press, Oxford England,1994.

[2] Khodabandeh, R., "Heat transfer in the evaporator of an advanced twophase thermosyphon loop", Int. Refrigeration, 28 pp., 2005.

[3] Palm, Khodabandeh, R., "Choosing working fluid for two-phase thermosyphon systems for cooling of electronics", proc. Interact 99, Maui, Hawaii, 1999.

[4] McDonald, T.W., Hwang, K.S., Diciccio, R., "Thermosyphon loop performance characteristics", Part1Experimental study, ASHRAE Trans. 83(Part II, No. 2467), 1997.

[5] Mehta, B., and Khandekar, S., 'Two-phase closed thermosyphon with nanofluids' 14th International Heat Pipe Conference (14th IHPC), Florianopolis, Brazil, April 22-27, 2007.

[6] Khandekar, S., Joshi, Y., and Mehta, B., "Thermal performance of closed two-phase thermosyphon using nanofluids", International Journal of
Thermal Sciences, 47 pp.659-667, 2008.

[7] Khandekar, S., Joshi, Y., and Mehta, B.," Thermal performance of closed two-phase thermosyphon using nanofluids "International Journal of Thermal Sciences 47, pp. 659-667, 2008.

[8] Choi, S.U.S, and Eastman, J. A. "Enhancing thermal conductivity of fluids with nano-particles", in: D.A. Signer, H.P. Wang (Eds.), Developments and Applications of Non-Newtonian Flows, in: FED, vol. 66, ASME, NY, pp. 99-103, 1995.

[9] Das, S.K., Putra, N., Thiesen, P., Roetzel, W., "Temperature dependence of thermal conductivity enhancement for nanofluids", ASME Trans. J. Heat Transfer 125 567-574, 2003.

[10] You, S.M., Kim, J.H., Kim, K.H., "Effect of nanoparticles on critical heat flux of water in pool boiling heat transfer", Appl. Phys. Letts. 83 (3374-3376), 2003.

[11] Bang, I.C., and Chang, S. H. , "Boiling heat transfer performance and phenomenon of $\mathrm{Al} 2 \mathrm{O} 3$ - water nanofluids from a plain surface in a pool", Int. J. Heat Mass Transfer48 (2407-2419), (2005).

[12] Rhi, S.H., Lee, Y., "Two-phase loop thermosyphon for cooling of electronic system", in: G.P. Celata, P. Di Marco, R.K. Shah (Eds.), Twophase Modeling an Experimentation, pp. 561-568, (1999).

[13] Yousefi T., Mousavi S.A., Farahbakhsh B., Saghir M.Z., "Experimental investigation on the performance of CPU coolers: Effect of heat pipe inclination angle and the use of nanofluids", Microelectronics Reliability, 2013, Article in press.

[14] Gillot, C., Bricard, A., and Schaeffer, C.," Single- and two-phase heat exchangers for power electronic components", Int. J. Thermal Sciences Vol.39,PP 826-832, 2000. 
[15] Beitelmal, M. H., and Patel, C. D.," Two-Phase Loop: Compact Thermosyphon", Internet Systems and Storage Laboratory, 2002.

[16] Mcglen, R. J., Jachuck, R., and Lin, S.," Integrated thermal management techniques for high power electronic devices", Applied Thermal Engineering, Vol.24, PP 1143- 1156, 2004.

[17] Collier, G., and Thome, J.," Convective Boiling and Condensation, Clarendon Press, Oxford, 1996.
[18] Das, S. K., Choi, U.S., Yu, W., and Pradeep, T., "Nanofluid Science and Technology", Wily-Interscience, 2007.

[19] Mousa, M. G., "Thermal Performance of Thermosyphon Charged by Nanofluid for Cooling Electronic Component", International Journal of Scientific \& Engineering Research, Volume 2, Issue 6, June2011. 